Original Article

\title{
ANTIFUNGAL EFFECT OF NIGELLA SATIVA EXTRACT ON FEMALE WISTAR RATS VULVOVAGINAL CANDIDIASIS MODEL
}

\author{
MUHAMMAD RUSDA \\ Division of Fertility, Endocrinology and Reproductive Medicine, Department of Obstetric and Gynecology, Faculty of Medicine, Universitas \\ Sumatera Utara \\ Email: mrusdaharahap@yahoo.com \\ Received: 22 Jan 2020, Revised and Accepted: 18 Mar 2020
}

ABSTRACT

Objective: To assess the antifungal effect of Nigella sativa extract on female Wistar rats vulvovaginal candidiasis.

Methods: This was an analytic study that assess the therapeutic effect of Nigella sativa in rats' vulvovaginal candidiasis model. The subjects were 28 rats that had been inoculated with Candida albicans and divided into 4 groups: control group (G1), fluconazole group (G2), Nigella sativa group (G3) and combination of Nigella sativa with fluconazole group (G4). Candida albicans colony was measured to assess the therapeutic effect of the treatment.

Results: There were no difference number of Candida albicans colony between all group before inoculation $(p=0,274)$ and after inoculation ( $p=$ $0,323)$. There were a significant decreased number of Candida albicans colony on the $72 \mathrm{~h}$ after the treatment between the three types of treatment with the control group (Nigella sativa group $\mathrm{p}=0,002$; Fluconazole group $\mathrm{p}=0,001$; Nigella sativa + fluconazole $\mathrm{p}=0,001$ ).

Conclusion: Nigella sativa has a potential antifungal effect by reducing the number of Candida albicans colonies.

Keywords: Nigella sativa, Antifungal, Candida albicans, Fungal inoculation, Pseudoestrus, Vulvovaginal candidiasis, Fluconazole

(C) 2020 The Authors. Published by Innovare Academic Sciences Pvt Ltd. This is an open access article under the CC BY license (http://creativecommons.org/licenses/by/4.0/) DOI: http://dx.doi.org/10.22159/ijcpr.2020v12i3.38308. Journal homepage: https://innovareacademics.in/journals/index.php/ijcpr

\section{INTRODUCTION}

Candida species are one of the commonest causes of vaginitis in healthy women of reproductive age. Vulvovaginal candidiasis (VVC) is characterized by vulvovaginal itching, redness and discharge. Candida albicans is the most common fungal infection of humans, causing Candidiasis [1].

Complications of vulvovaginalis candidiasis (VVC) that often occur is a pelvic inflammatory disease which can ultimately cause infertility in sexually active women and chorioamnionitis which leading miscarriage or premature birth in women who are pregnant. Immediate and proper management of VVC must be done to prevent complications [2, 3].

Nigella sativa is a member of the Ranunculaceae family and has been used as a natural food and medicine which grows in Asia and the Middle East [4]. It contains Thymoquinone, Thymohydroquinone, Dithymoquinone and Thymol. Thymoquinone inhibits the oxygen cycle as an inflammatory balance process with lipo-oxygenizes. Nigella sativa has pharmacological effects as antimicrobial, antiinflammatory, immune stimulation and anti-cancer properties $[5,6]$.

The inhibitory effect of fungal by Nigella sativa extract has been proved by a study both in vitro and in vivo against some pathogenic fungal such as Candida albicans, dermatophytes, non-dermatophytes and some aflatoxin-producing fungi. It had shown that Nigella sativa had a high inhibitory effect on candidiasis in rats in vivo and can reduce the number of Candida albicans 5-fold in the kidneys, 8-fold in the liver and 11-fold in the spleen. The antifungal effect of Nigella sativa treatment for a single day on rats that had been inoculated with the Candida albicans apparently inhibited the growth of this pathogen $[7,8]$.

Further research is needed to evaluate the antifungal activity of Nigella sativa in vivo, especially in the vulvovaginal candidiasis model [9].

\section{MATERIALS AND METHODS}

\section{Methods}

This experimental research was conducted in July-October 2019 on Animal House-Faculty of Mathematics and Natural Sciences,
Universitas Sumatera Utara to asses the antifungal effect of Nigella sativa extract on vulvovaginal candidiasis. Ethical clearance is obtained from Animal House-Faculty of Mathematics and Natural Sciences, Sumatera Utara University.

This study use 28 female Wistar rats (Rattis norvegicus $s p$ ) aged 2-3 mo with a weight range of 200-250 grams that had fulfilled the inclusion and exclusion criteria. Before we do inoculation, we give estradiol valerate $2 \mathrm{mg}$ subcutaneously intraperitoneal $3 \mathrm{~d}$ before inoculation and $4 \mathrm{~d}$ after inoculation to make the rat in pseudoestrus state that needed to maintenance the Candida albicans, and prevent self-healing.

The breeding of Candida albicans was held in the microbiology laboratory, Universitas Sumatera Utara General Hospital. By swapping the vagina with a cotton swab dipped in ATCC 14503 contained 3 McFarland Candida albicans cells, the inoculation was done.

The Nigella sativa extract was given from the pharmacological laboratory, Faculty of Pharmacy, Universitas Sumatera Utara, using Sodium Carboxymethyl cellulose ( $\mathrm{Cmc} \mathrm{Na}$ ) in order to obtain the extract of Nigella sativa $5 \mathrm{mg} / \mathrm{ml}$.

The samples were divided into 4 groups: 7 rats in the control group, 7 rats were given Nigella sativa extract $5 \mathrm{mg} / \mathrm{ml}$ with a dose of 6.6 $\mathrm{ml} / \mathrm{kg}$ of body weight, 7 rats were given $10 \mathrm{mg} / \mathrm{kg}$ of body weight of fluconazole, and 7 rats were given a combination of Nigella sativa extract $6.6 \mathrm{ml} / \mathrm{kg}$ of body weight and fluconazole $10 \mathrm{mg} / \mathrm{kg}$ of body weight. The treatment was given for $72 \mathrm{~h}$ after $24 \mathrm{~h}$ inoculation. The colonies of Candida albicans on the rat's vagina were measured before inoculation and $24 \mathrm{~h}$ after therapy. Vaginal smear samples were obtained, incubated for $48 \mathrm{~h}$ on temperature $37^{\circ} \mathrm{C}$ and counted in the microbiology laboratory of the Universitas Sumatera Utara Hospital.

Data analyzed was using SPSS 22. We used Kruskal Wallis to assess differences in the four groups, $\mathrm{T}$ independent test and Mann Whitney, to assess differences in the number of Candida albicans colonies in all four groups. 


\section{RESULTS}

Table 1: Colonies count of Candida albicans before inoculation

\begin{tabular}{|c|c|c|c|c|c|c|}
\hline \multirow[t]{2}{*}{ Group } & \multirow[t]{2}{*}{$\mathbf{n}$} & \multicolumn{4}{|c|}{ Colonies count of Candida albicans, CFU/Plate } & \multirow[t]{2}{*}{$\mathbf{p}$} \\
\hline & & Mean & SD & Median & Min-Max & \\
\hline G1 & 7 & 0,14 & 0,38 & 0 & $1-1$ & $0,274^{\mathrm{a}}$ \\
\hline G2 & 7 & 10 & 18,68 & 0 & $0-51$ & \\
\hline G3 & 7 & 2,14 & 2,48 & 2 & $0-6$ & \\
\hline G4 & 7 & 0,57 & 0,79 & 0 & $0-2$ & \\
\hline
\end{tabular}

aKruskal Wallis, Note: G1 = control group, G2 = fluconazole group, G3 = Nigella sativa group, G4 = fluconazole+Nigella sativa group

The highest mean of the number of Candida albicans colonies was found on the fluconazole group with $10+18,68 \mathrm{CFU} /$ plate and lowest mean on the control group with $0,14+0,38 \mathrm{CFU} /$ plate. There was no difference of mean number colonies between four groups before inoculation with $\mathrm{p}=0,274$.

After the inoculation, the remeasurement of vaginal colonies was done. The highest number of Candida albicans colonies was found on the control group with $237,86+106,46 \mathrm{CFU} /$ plate and the lowest fungal colonies were in Nigella sativa group with $164,57+124,69$.
There was no difference of mean number colonies between four groups after inoculation with $\mathrm{p}=0,323$.

After $72 \mathrm{~h}$ treatment, the therapeutic effect measured, we found that the lowest number of Candida albicans colonies belong to the combination group with $0,14+0,38 \mathrm{CFU} /$ plate, meanwhile, the highest was in the control group with $130,43+117,76 \mathrm{CFU} /$ plate. There was a significant difference of the mean number of colonies between four groups after $72 \mathrm{~h}$ of treatment $(\mathrm{p}<0,001)$. From Post Hoc Test, it was seen that there were significant mean differences between Control group and three treatment groups $(\mathrm{p}<0,05)$

Table 2: Colonies count of Candida albicans after inoculation

\begin{tabular}{llllll}
\hline Group & $\mathbf{n}$ & \multicolumn{2}{c}{ Colonies Count, CFU/Plate } & p \\
\cline { 3 - 5 } & & Mean & SD & Median & Min-Max \\
\hline G1 & 7 & 237,86 & 106,46 & 300 & $68-300$ \\
G2 & 7 & 136,86 & 115,77 & 78 & $28-300$ \\
G3 & 7 & 164,57 & 124,69 & 66 & $60-300$ \\
G4 & 7 & 210 & 95,67 & 243 & $56-300$ \\
\hline
\end{tabular}

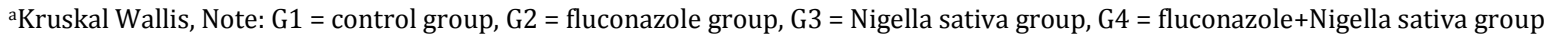

Table 3: Colonies number of Candida albicans after $72 \mathrm{~h}$ treatment

\begin{tabular}{|c|c|c|c|c|c|c|c|c|c|}
\hline \multirow[t]{2}{*}{ Group } & \multirow[t]{2}{*}{$\mathbf{n}$} & \multicolumn{4}{|c|}{ Colonies number, CFU/Plate } & \multirow[t]{2}{*}{$\mathbf{p}$} & \multicolumn{3}{|c|}{ Post hoc } \\
\hline & & Mean & SD & Median & Min-Max & & G2 & G3 & G4 \\
\hline G1 & 7 & 130,43 & 117,76 & 62 & $43-300$ & $<0,001^{\mathrm{a}}$ & $0,001^{b}$ & $0,002^{b}$ & $0,001^{b}$ \\
\hline G2 & 7 & 0,43 & 1,13 & 0 & $0-3$ & & & $0,101^{b}$ & $0,917 \mathrm{c}$ \\
\hline G3 & 7 & 1,14 & 0,9 & 1 & $0-2$ & & & & $0,027^{b}$ \\
\hline G4 & 7 & 0,14 & 0,38 & 0 & $0-1$ & & & & \\
\hline
\end{tabular}

aKruskal Wallis, bMann Whitney, ${ }^{\mathrm{c} T}$ Independent, Note: G1 = control group, G2 = fluconazole group, G3 = Nigella sativa group, G4 = fluconazole+Nigella sativa group

\section{DISCUSSION}

The environment changing of vaginal candidiasis will quickly recover so that the infection will heal quickly without creating a pseudoestrus situation [10]. To create, support and maintenance pathogens for vulvovaginalis candidiasis rat model, special treatment was needed by giving estradiol valerate $2-5 \mathrm{mg}$ subcutaneously intraperitoneal $3 \mathrm{~d}$ before inoculation and $4 \mathrm{~d}$ after to decrease rat immunity or creating a pseudoestrus situation. If needed, it can be repeated weekly [11,12].

The number of Candida albicans fungal colonies in all groups was increased (Control group: 0,14+0,38 vs 237,86+106,46, Fluconazole: $10+18,68$ vs $136,86+115,77$, Nigella sativa: $2,14+2,48$ vs $164,57+124,69$; Combination group: $0,57+0,79$ vs $210+95,67)$. This indicated that the rats successfully became vulvovaginalis candidiasis model.

Nigella sativa Linn, Ranunculaceae family, was grown in many parts of the world, especially the Mediterranean region, North Africa, the Middle East and parts of Asia and used by herbal therapy for many diseases [7].

The component of Nigella sativa was thymoquinquinone (TQ), alcaloid (nigellicines and nigelledine), saponins (alpha-hederin), flavonoids, proteins, fatty acids, and many others, which have various therapeutic effects [13].

Nigella sativa extract has the strongest antifungal effect against various pathogenic fungal strains, including methanol, ethanol and chloroform extracts [6]. Even water extracts from Nigella sativa seeds showed an inhibitory effect on candidiasis in rat $[14,15]$. From the results of this study, the administration of Nigella sativa extract with Sodium Carboxymethyl cellulose can reduce the number of vaginal colonies of the Candida albicans $(\mathrm{p}=0,002)$.

Based on the treatment groups comparison, all the three treatment groups include were fluconazole group, Nigella sativa extract group and combination of Nigella sativa and fluconazole extract group can reduce the number of fungal colonies compared with the control group ( $\mathrm{p}=0,001 ; \mathrm{p}=0,002 ; \mathrm{p}=0,001)$.

\section{CONCLUSION}

Nigella sativa has a potential antifungal effect by reducing the number of Candida albicans colonies after $72 \mathrm{~h}$ administration.

\section{FUNDING}

Nil

\section{AUTHORS CONTRIBUTIONS}

All the authors have contributed equally.

\section{CONFLICT OF INTERESTS}

Declare none 


\section{REFERENCES}

1. Association for Genitournary Medicine. National guideline on the management of vulvovaginal candidiasis; 2002

2. Bitew A, Abebaw. Vulvovaginal candidiasis: species distribution of candida and their antifungal susceptibility pattern. Bmc Women's Health 2018;18:1-10.

3. Cassone A, Sobel JD. Experimental models of vaginal candidiasis and their relevance to human candidiasis. Infect Immun 2016;84:1255-61.

4. Ahmad A, Husain A, Mujeeb M, Khan SA, Najmi KA, Siddique NA, et al. A review on therapeutic potential of nigella sativa: a miracle herb. Asian Pacific J Trop Biomed 2013;3:337-52.

5. Fard FA, Zahrani ST, Bagheban AA, Mojab F. Therapeutic effects of nigella sativa linn (Black Cumin) on candida albicans vaginitis. Arch Clin Infect Dis 2015;10:1-5.

6. Forouzanfar F, Fazly Bazzaz BS, Hosseinzadeh. Black cumin (Nigella Sativa) and its constituent (Thymoquinone): a review on antimicrobial effects. Iranian J Basic Med Sci 2014;17:929-38.

7. Kooti W, Hasanzadeh Noohi Z, Sharafi Ahvazi N, Ashtary Larky D. Phytochemistry, pharmacology, and therapeutic uses of black seed (Nigella sativa). China Pharmaceutical 2016;14:73245.

8. Moghim H, Taghipoor S, Shahinfard N, Kheiri S, Panahi R. Antifungal effects of zataria multiflora and nigella sativa extracts against candida albicans. J Herb Med Pharmacol 2015;4:138-41.

9. Shokri H. A review on the inhibitory potential of nigella sativa against pathogenic and toxigenic fungi. Avicenna J Phytomed 2016;6:21-33.

10. Martinez RC, Franceschini SA, Patta MC, Quintana SM, Candido $\mathrm{RC}$, Ferreira JC. Improved treatment of vulvovaginal candidiasis with fluconazole plus probiotic lactobacillus rhamnosus GR-1 and lactobacillus reuteri RC-14. Lett App Microbiol 2009;48:269-74

11. Fidel PL, Cutright J, Steele C. Effects of reproductive hormones on experimental vaginal candidiasis. Infection Immunity 2000;68:651-7.

12. Joly V, Yeni P. Rodent models of candida sepsis. In: Handbook of animal models of infection. Zak 0, Sande M. Eds. Academic press: Cambridge, MA USA; 1999. p. 650-7.

13. Mohammed AENA, Al-Suwaieg SB. Effects of nigella sativa on mammals' health and production. Adv Anim Vet 2016;4:1-7.

14. Tavakkoli A, Mahdian V, Razavi B. Hosseinzadeh. Review on clinical trials of black seed (Nigella Sativa) and its active constituent, thymoquinone. J Pharmacopuncture 2017;20:17993.

15. Gharby S, Harhar, Guillaume D, Roudani A, Boulbaround S, Ibrahimi M, et al. Chemical investigation of nigella sativa L. seed oil produced in morocco. J Saudi Soc Agric Sci 2015;14:172-7. 